Journal of Social Sciences 8 (2): 177-181, 2012

ISSN 1549-3652

(C) 2012 Science Publications

\title{
Developing Inner Peace and Joy through Art Education
}

\author{
Susmita Lakhyani \\ Department of Education, University of Delhi, Delhi, 10007, India
}

\begin{abstract}
Problem statement: Art Education has been given place in the curriculum yet there is a general misconception that the subject Art is of lesser importance and treated as a mere entertaining fringe. The present study looks into this matter. The basic key question, therefore, is-Does process of art education that is art instruction, promotes creative aspects of students and develops inner peace? It is with reference to Teacher education course. Approach: For the study, a workshop on art was organised and 400 B.Ed. students (pre-service teachers) were taken. Most of these students had studied art only till 8th standard while few of them had no experience of any art class in school. They were hesitant to paint and had lot of misconceptions about art. The workshop included slide show, discussion and interpretation, meditation, listening music, painting on the spot and writing the experience of going through the workshop. Data was analysed qualitatively. Results: It was concluded that art education promotes: unique perception, feelings, sensitivity, symbolic association, imagination, originality, unique idea, imagination, self-realization and observation which are the aspects of creativity. It was also analysed from the data that art education made subjects feel relaxed; satisfied; fresh; feeling of other worldliness; contented; inner peace; joy; happy; self-realization; inspired, motivated and confident to create; sense of freedom; no limitations, no boundaries and no hesitations; emergence of new ideas and imagination; and awareness of inner potentials. Conclusion: Art education promotes peace and joy in an individual and it's important in one's growth.
\end{abstract}

Key words: Meditation, painting, visual arts learning of experiencing, association, imagination

\section{INTRODUCTION}

Education starts with acquisition of knowledge and ends with its application. In other words it is a process of expression of all potentials of which a human being is full of. It is believed that human beings are endowed with unique powers which are to be brought out or expressed. Wickiser (1957) believes that "In fact expression is the culmination of learning, of experiencing; it is completion of the process". The whole process, in fact, has been cognized as process of creativity. Education enhances this creativity. Art is one of the most important factors of this process of education to promote this creative aspect of human beings. As it is stated that the Sanskrit literature considers a human being incomplete if he is not educated in art and literature. In one of the Sanskrit verses it is said that without art, music and literature a human being is an animal without tail and horns. Mago (2001) states, "According to Sukara Niti Saar, art was a more complete discipline (to develop a person's mind) than learning through reading and writing".

Though art education has been given place in the curriculum yet there is a general misconception that the subject Art is of lesser importance in comparison to the other regular subjects, such as Mathematics, Science. But it is realised that art should become an important component of learning and not be treated as a mere entertaining fringe. According to (NCERT, 2005) it should be made compulsory subject up to class-X. It further states: "Since this is an activity based, experiential subject, it gives scope for observation, imagination and visualisation in the process of creativity. Every individual child has all types of emotions, which need to come out of the child's inner-self; art education helps them in this process".

The present study looks into this matter. The basic key question, therefore, is-Does process of art education, i.e., art instruction, promotes creative aspects and develops inner peace and joy in students? It is with reference to Teacher education course.

For the study, workshop on art was organised and 400 B. Ed students (pre-service teachers) of different batches, from the Department of Education, University of Delhi were taken. Most of these students had studied art only till 8th standard while few of them had no experience of any art class in school and were hesitant to paint.

Objectives: The objectives of the workshop were- 
- To make the subjects observe, perceive, concentrate, symbolically associate, integrate ideas and meditate

- To spur the imagination and create an environment for new ideas and feelings to emerge

- To motivate and encourage subjects to paint felt ideas or experiences freely, confidently and feel relaxed

\section{MATERIALS AND METHODS}

To achieve the above mentioned objectives, workshop was divided into following four phases, keeping in mind their existing level of understanding:

Phase I: Discussion on Art

Phase II: Slide Show

Phase III: Painting and Feedback

Phase IV: Analysis of Paintings

Phase I: Discussion on art: An introduction about Art was given, which mainly focused on the meaning of Art. It also focused on the key questions of why it is important to view works of art and what relevance it has in our life. Clarifications to general misconceptions were given such as:

- Art is all about just making the things in a realistic way

- I cannot draw a single straight line so I am not creative

- Not everybody has the creative power

After some discussion and clarification of misconceptions the subjects were shown the works of different artists (including child art) in the form of slides. During the slide show, the subjects were asked to share their interpretations or ideas or what they felt about a particular work of art on screen. Simultaneously (in few slides) the artist's idea behind the creation was discussed. The subjects interpreted the slides in their own way and shared it confidently. For example Fig. 1 titled 'communion of spirits' by the artist (based on the idea: an angel is urging the spirits saying "In the silence of night I offer you my wings to come across the sea". An angel wants the sleeping souls to get awakened to the ultimate truth.) Was interpreted by the subjects in different ways as:

"The basic thing I noticed in the picture is the use of colour such that a three dimensional effect is originating through the shades of the waves. It seems as if these waves are going to come out of it. The moon shown in the picture is shining brightly. The painting gives me the feeling as all of us will have to go to heaven in the end and we will have to go and give the reply to each question asked by the God and explain our deeds in the words".

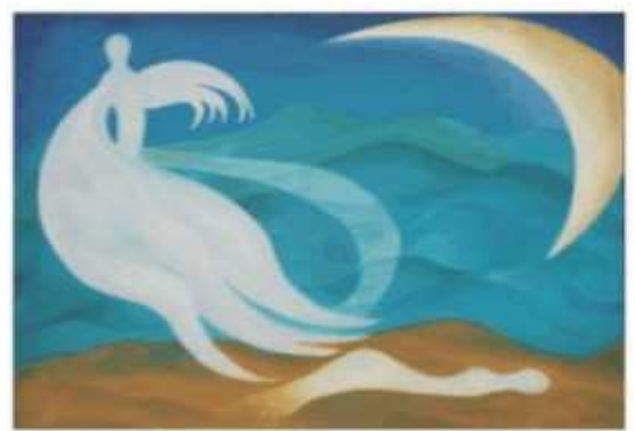

Fig. 1:(Communion of spirits) by Susmita lakhyani oil on canvas

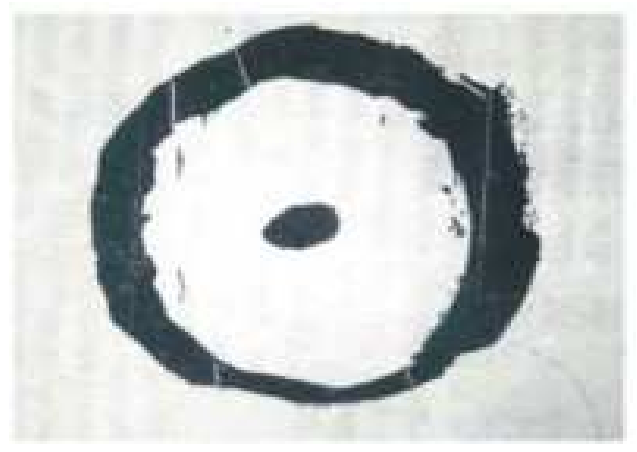

Fig. 2: (Me in my house) by $21 / 2$ years child

"This painting appealed to me as this is showing a calm death. This really shows me or evokes in me the kind of imagination as if I am dead and lying calmly. It shows that an angel has come to take my soul and that soul has

merged into the angel. This painting is showing me what I want to be after my death. The presence of a crescent moon is also showering a cool effect".

"In the background are misty hills, perhaps the sand dunes of a desert on a night illuminated by the shining rays of a moon. In the foreground is a man, asleep. Out of him emerges the dream of an angel. The scene is very soothing".

"To me this painting signifies a dream. The white lying down figure is sleeping whose consciousness escapes into that realm of fantasy where even though things look familiar, they are not. The green hills have an unreal quality to them, as does the carved crescent moon. The colours flow into each other in the creation of the background, the moon and the earth. In many ways this painting reflects freedom. The freedom one acquires in the most intense dreams. The freedom to explore, be and fly".

"I found nice colour combinations. And the meaning it convey really appeals to me, that whatever height you may achieve in your life and career, that 
too high you might have been flying, but still your shadow will lie on the ground. No one should forget one's groundings".

The child who painted Fig. 2 expressed it as 'me in my house' stated Jeswani (1966). It was interpreted in the workshop as a 'hole', 'cycle tyre', 'face', 'a patch on moon', 'cross section of tree trunk', 'target point' and so on.

Phase III: Painting and feedback: After the viewing of slides the instrumental music composed by Beethoven was played. Subjects were asked to listen to it for few minutes with closed eyes and let the feelings flow. Then, they were asked, to open their eyes, when they felt like and start painting anything (such as any situation, incident, place and so on.) which is close to their heart on sheets in the medium of their choice. Music was softly being played in the background during the time subjects were painting. After completing the painting subjects were asked to write the idea or thought behind their painting, as well as their (feedback) experience about the whole workshop.

Phase IV: Analysis of paintings and feedback: Subjects' paintings and their responses were analysed qualitatively on following aspects:

- Symbolic association

- Expression

- Perception

- Balance of colour

- Balance of Space

- Observation

- Imagination

- Composition

- Originality

- Integration of idea

It was observed that the subjects verbally expressed their 'felt ideas' and 'honest interpretations', while the slides were being discussed and in their paintings unique expressions and felt ideas were reflected. It was observed that discussion on the meaning of art and misconceptions brought confidence in them to share their interpretations on the works of art viewed.

In the beginning of the workshop, during the discussion, the subjects shared that they were not able to think beyond the conventional forms of mountains; huts; sceneries with a boat and sun; and conventional geometrical or floral designs. But, it was analyzed from their works (which they did after discussions, viewing of slides and silently listening to music) that they were able to think beyond the conventional ideas and they expressed what they really felt and experienced. This is reflected in the following examples of the paintings (Fig. 4, 6, 8 and 9) done by the subjects. The subjects, also, shared the idea behind their work of art.

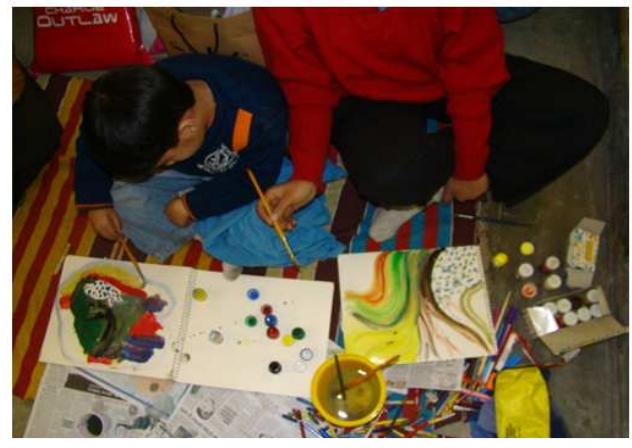

Fig. 3: The subject creating Fig. 4

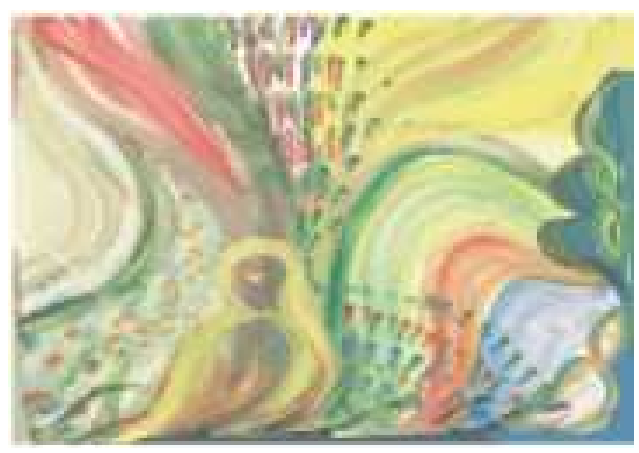

Fig. 4: Mother and child

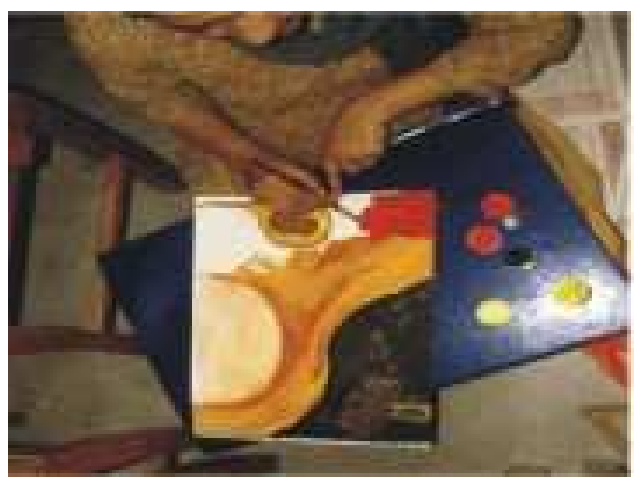

Fig. 5: The subject creating Fig. 6

Example-1: The subject (Fig. 3) who created Fig. 4 writes: "I've shown a kind of freedom which I felt during painting. I've shown myself with my child. My child is always present at the back of my mind, trying to nurture him with warmth and care just like the shade from a tree".

Example-2: The subject (Fig. 5) wrote about her painting (Fig. 6): “It represents a women's struggle, for freedom, for voice --- since the time she was in her mother's womb (how? --- even I don't know myself). 


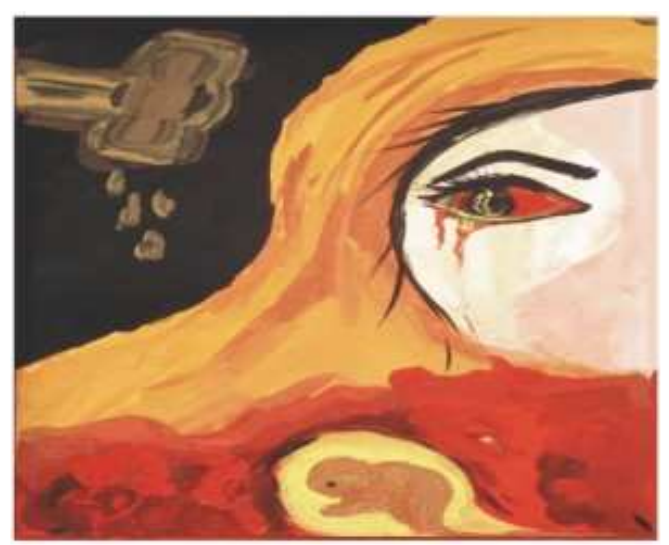

Fig. 6: Women's struggle

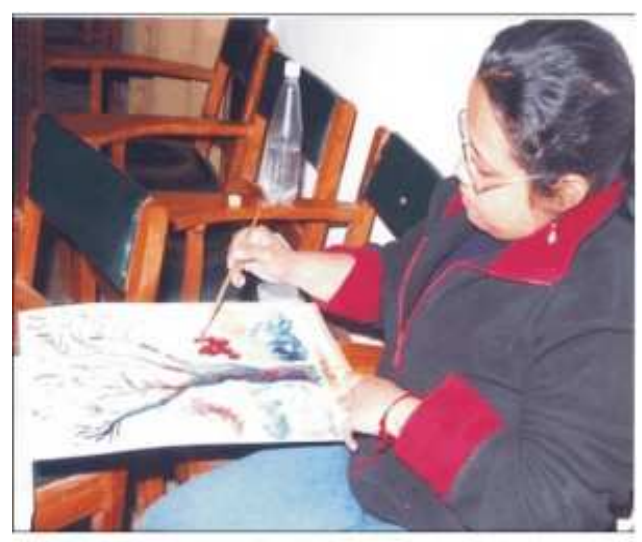

Fig. 7: The subject creating Fig. 8

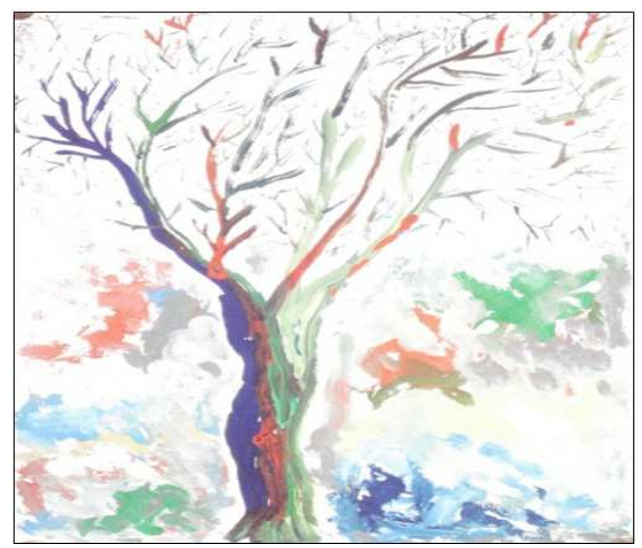

Fig. 8: Senescence

It represents a girl's pain, tears suppressed for so long, are now blood. The hammer is a representation of all the forces surrounding her, reducing her space....... which is so small, that it now confides only to her heart, she's succumbing to it...... and "It's killing".

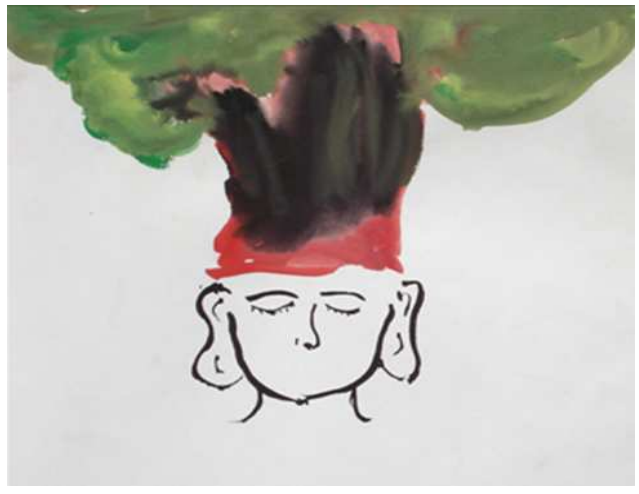

Fig. 9: Meditation

Example 3: The subject (Fig. 7) titled the painting Fig. 8 as 'Senescence' and writes: "Senescence is the period of deterioration, a phase before death. We often connect it with something negative, but I find a hidden beauty in the process. This is what I have tried to depict in this painting. It's an autumn tree, leafless, in its last stage, but I have colorful hues and shades because for me there is beauty even in this particular phase of life".

Example-4: The subject writes about his/her painting (Fig. 9) as: "Knowledge increases more in listening than talking. A person should meditate with a peaceful mind and listen to truthful words to increase his knowledge. Knowledge is like a tree which grows when one listens more".

After the subjects completed their paintings they were asked to write about their 'experience of the workshop' or what did they feel about the workshop. Some of the extracts are as under:

"It gave me a chance to meet myself and somehow I came to know that what I want, some day, may be that because inner peace has no face, type, choice. It can meet you anywhere, nowhere or everywhere. Another thing I came to know that inner desires can be fulfilled through a different medium called a 'blank canvas' on which you can express yourself without any limitation or hesitation, without any boundaries or restrictions".

"I have had, for the first time, this kind of experience in my whole life. Earlier, I felt no connectivity with art and it was alien to me but, now, I've realized that really 'art is a part of life' and there is a need to recognize it. It doesn't mean photocopying something as it is, but it means to interpret one's feeling with colours in very simple and lucid way. I experienced inner peace during the workshop".

"After seeing those slides of paintings and participating in the discussion I've started appreciating art.......It has been a source of pleasure and content. After drawing my thoughts and feelings on the study, I am really feeling relieved and relaxed". 


\section{J. Social Sci., 8 (2): 177-181, 2012}

"While painting nothing was there in my mind: no assignment, no house hold things. Truly this was an overwhelming opportunity in which all students were painting together".

"I enjoyed viewing the paintings been showed, I was able to guess who the painter could be and it turned out to be right, that was wonderful. I never thought I would be able to recognize painters from paintings".

"I enjoyed the painting session, it was lovely to feel free to do as we pleased and express ourselves".

"Something was bothering me, I got a chance to move away from those, thanks for this meditative experience. I am now more at peace within myself. My painting moves from mayhem to concrete things".

".......forgot the world outside and was led to a different place where I was alone with my thoughts and thus was able to reflect my experience and expression in the form of painting".

"Through this my imagination got some pause and I also thought something unique. I am so happy".

"It was a moment for me where I can evaluate my artistic expression on my own".

"The whole experience was inspiring enough for me to draw a painting from my heart. I learnt something new of expressing through colors".

"All my hidden feelings, thoughts and expression got a creative outlet".

"It was a moment to relax and just let go of your emotions. I really enjoyed myself".

"I enjoyed while painting more than I expected".

"Wonderful stress bursting experience... More of these workshops should be there to release weeklong bottled up frustrations".

"This was a new, but great experience for me. I found a new sense of art in me".

"I was enjoying very much. In the beginning I wasn't able to understand what to do, later on, new ideas started coming to my mind. My hand on its own started painting".

"It seemed to me that I would get bored in this class. I didn't want to come, but, still, I came to this class. But, as soon as I entered, the environment and paintings seemed to be very enchanting and after seeing them I made four paintings basing on my imagination".

"I would like to say one thing very clearly the environment was really very-very mesmerising. I used to be fearful about painting. But today I came to know that I have to express my inner feelings. New ideas came to my mind on its own and the brush started doing its work".

"This has been an unforgettable experience for me to sit, forget the world and color, paint... express... opportunity to let my dream come true. A part of me came on study today. It was an out of the body experience".

"After going through the slides and discussions a lot of ideas started flowing in my mind. I started feeling to draw although I had never painted and don't know how to draw. I've enjoyed doing painting. Whatever came to my mind I've tried to make that? From now on, I would like to do more paintings..."

"It was an awesome, amazing experience, especially for a science student like me who has never been exposed to such a workshop. Helped in sensitizing me towards art and artists and feel the creativity inside me".

"It was a very different experience; Visuals just started flowing through your mind... very Relaxing".

\section{RESULTS AND DISCUSSION}

Analyzing the paintings (done by the subjects) and the above responses of the subjects (related to their experience of the workshop) it can be said that the subjects had attended this kind of workshop for the first time. It can be observed that the subjects felt: relaxed; satisfied; fresh; feeling of other worldliness; contented; inner peace; joy; happy; self realization; inspired, motivated and confident to create; sense of freedom; no limitations, no boundaries and no hesitations; emergence of new ideas and imagination; and awareness of inner potentials.

The subjects felt the environment inspiring and motivating which lead many ideas and imagination flow in them. This feeling of the subjects can be observed in their paintings as well. Their paintings reflected: unique perception, feeling, sensitivity, symbolic association, imagination, originality, unique idea, imagination, self realization and observation.

\section{CONCLUSION}

Consequently, it can be concluded that training in art helped the subjects to perceive, imagine and express new ideas in their unique and original way and feel inner peace and joy.The general tendency to take Art as a fringe subject should be done away with amongst the parents and school administrators. Art should be given an equal footing in the curriculum as other theoretical subjects. There is need to create an awareness about the positive role Arts play in ones life.

\section{REFERENCES}

Jeswani, K.K., 1966. Art in Education. 1st Edn., Atma Ram, Delhi, pp: 194.

Mago, P.N., 2001. Contemporary Art in India: A Perspective. 1st Edn., National Book Trust New Delhi, India, ISBN: 8123734204, pp: 225.

NCERT, 2005. National curriculum framework 2005. 1st Edn., National Council of Educational Research and Training, New Delhi, pp: 140.

Wickiser, R.L., 1957. An introduction to art education. 1st Edn., Harrap, London, pp: 342. 